\title{
Enhancement in the Electrical and Thermal Properties of Ethylene Vinyl Acetate (EVA) Co-Polymer by Zinc Oxide Nanoparticles
}

\author{
Jose Sebastian1, Eby T. Thachil1, Jobin Job Mathen², Joseph Madhavan², Prince Thomas ${ }^{3}$, \\ Jacob Philip4, M. S. Jayalakshmy4, Shahrom Mahmud5, Ginson P. Joseph ${ }^{3 *}$ \\ ${ }^{1}$ Department of Polymer Science and Rubber Technology, Cochin University of Science and Technology, Kerala, \\ India \\ ${ }^{2}$ Department of Physics, Loyola College, Chennai, India \\ ${ }^{3}$ Department of Physics, St. Thomas College, Palai, India \\ ${ }^{4}$ Department of Instrumentation, Cochin University of Science and Technology, Kerala, India \\ ${ }^{5}$ School of Physics, Universiti Sains Malaysia, Minden, Malaysia \\ Email: joseuce@gmail.com, etthachil@gmail.com, jobinjobuv@gmail.com, jmadhavang@yahoo.com, \\ princealani@gmail.com, jphilip6012@gmail.com, jayalakshmy.ms@gmail.com, ${ }^{*}$ ginsonpj@gmail.com, \\ "ginsonpjoseph@gmail.com
}

Received 21 May 2015; accepted 4 July 2015; published 7 July 2015

Copyright (C) 2015 by authors and Scientific Research Publishing Inc.

This work is licensed under the Creative Commons Attribution International License (CC BY). http://creativecommons.org/licenses/by/4.0/

(c) (i) Open Access

\section{Abstract}

EVA/ZnO nanocomposites of $1 \%, 2 \%$ and $4 \% \mathrm{ZnO}$ were fabricated by direct probe sonicator method. The ZnO nanopowders were prepared by solvothermal method. As the particle size of the filler incorporated to the polymer matrix decreases, the properties of the polymer-filler interface show dominance over its bulk properties. The dielectric constant and dielectric loss of the composites at ambient temperatures are found to decrease with increasing frequency. The thermal analysis using TGA-DTA is also performed and it is found that the thermal stability of the nanocomposites increases with increasing the filler concentrations. The thermal parameters such as thermal diffusivity $(\alpha)$ and thermal effusivity $(e)$, the thermal conductivity $(k)$ and heat capacity $\left(C_{p}\right)$ were studied using photopyroelectric technique. The band gap of the samples was also determined and found to decrease with increasing filler concentrations. The tensile strength and peel strength of the samples were also investigated and it is found to increase with small inclusion of filler material.

\section{Keywords}

Composite Materials, Polymers, Differential Thermal Analysis (DTA), Dielectric Properties

\footnotetext{
${ }^{*}$ Corresponding author.
}

How to cite this paper: Sebastian, J., et al. (2015) Enhancement in the Electrical and Thermal Properties of Ethylene Vinyl Acetate (EVA) Co-Polymer by Zinc Oxide Nanoparticles. Open Journal of Composite Materials, 5, 79-91. 


\section{Introduction}

Composites have attracted attention of material scientists as it can combine advantages of different materials. In recent years, material scientists are looking for nano-composites based on polymer matrix due to several added advantages. The advantages include balanced physical and mechanical properties, ease of processability and low production cost [1]. Many previous works have been carried out to improve the optical and electrical properties of polymers through suitable doping [2] [3]. Polymer based dielectric materials can give flexible and light weight electrical devices. It is discovered that nano-particles like $\mathrm{Al}_{2} \mathrm{O}_{3}, \mathrm{TiO}_{2}, \mathrm{SiO}_{2}$ etc. heterogeneously distributed within the polymer matrix can enhance dielectric properties [4]. Murugaraj and co-workers [5] have fabricated polymer-alumina nano-composites with improved dielectric characteristics. Carbon nanotubes (CNTs), carbon black, carbon nanofibres (CNF) as well as single and multi wall carbon nano tubes (SWNTs \& MWNTs) have been incorporated to polymer matrix to use as antistatic coatings [6].

During recent years, colloidal and semiconducting nano particles have attracted a great deal of attention for both researchers and industrialists. Different types of group II-VI nano particles including ZnSe, CdS, CdSe, CdTe are found to be used extensively for light-emitting diode [7], solar cell [8], biomedical tag [9] and laser [10] applications. Nanocrystals (NCs) of semi conducting materials are used in optoelectronic devices like lasers and transistors [11] [12]. The ZnO used in this study is one such type of nanopowder having excellent ultraviolet and visible photoluminescence [13], and it is a semiconductor having large exciton binding energy (60 meV). It has got diverse applications in photovoltaic cells, variable resistors, as fully transparent thin film transistors and in short wavelength light emitting diodes.

Wide variety of polymers are found application in the synthesis of nano composites. They form the continuous phase termed as the matrix of the composite. Polymer matrix composites (PMC) with ceramic and metals as fillers have been developed to improve electrical properties like dielectric permittivity [14] [15]. Poly methylmethacrylate [16] [17], epoxy [18], poly(vinyl alcohol) [19], polyaniline [20] [21] are extensively used as the matrix for composites.

Poly (ethylene-co-vinyl acetate), EVA, was used as the base polymer in this experiment as they are compatible even with inert fillers. EVA is noted for its rubbery nature along with gloss, permeability and good impact strength. EVA-TiO ${ }_{2}$ nanocomposites were investigated for the effect of $\mathrm{TiO}_{2}$ particle size on the co-efficient of thermal expansion [22]. EVA copolymer irradiated with gamma rays can cause modification in its electronic structure [23]. Ethylene vinyl acetate is particularly used in electrical industry as cable insulating material due to good stress cracking resistance.

The II-VI semiconducting materials show significant properties from the optoelectronic point of view [24]. In the bulk form and in the quantum dot form these materials exhibit high density and quantum confinement. This paper deals with the effect of $\mathrm{ZnO}$ nanopowder on the electrical, optical, mechanical properties EVA polymer matrix and reported for the first time.

\section{Synthesis of $\mathrm{ZnO}$ Nanoparticle}

A solution of $0.2 \mathrm{M}-\left(\mathrm{CH}_{3} \mathrm{COO}\right)_{2} \mathrm{Zn} \cdot 2 \mathrm{H}_{2} \mathrm{O}$, Zinc Acetate, was prepared by dissolving $4.39 \mathrm{gm}$ of $\left(\mathrm{CH}_{3} \mathrm{COO}\right)_{2} \mathrm{Zn} \cdot 2 \mathrm{H}_{2} \mathrm{O}$ in $100 \mathrm{ml}$ of methanol in a beaker and the mixture was kept stirred for 15 minutes. Another mixture of $0.5 \mathrm{M}-\mathrm{NaOH}$ and methanol was prepared by dissolving $0.5 \mathrm{gm}$ of $\mathrm{NaOH}$ in $25 \mathrm{ml}$ of methanol and was kept for stirring for 15 minutes. Then the $\mathrm{NaOH}$-methanol mixture was added to the basic solution and the reaction mixture was kept stirred for 30 minutes. The prepared solution was kept in autoclave for drying at $180^{\circ} \mathrm{C}$ for 5 hours to obtain nano-sized $\mathrm{ZnO}$ particles. Dried $\mathrm{ZnO}$ nanoparticles, white in colour was obtained. The size of the nanopowder was determined using TEM and it as confirmed $20 \mathrm{~nm}$ (Figure 1).

\section{Synthesis of Zn0/EVA Polymer Nanocomposite}

Poly (ethylene-co-vinyl acetate), EVA copolymer used for the experiment was obtained from ExxonMobil Chemicals, Singapore. The vinyl acetate content of the copolymer used was $9.4 \mathrm{wt} \%$ (Density $-0.931 \mathrm{~g} / \mathrm{cm}^{3}$, Melt Flow Index-2.1 g/10min @ $190^{\circ} \mathrm{C}, 2.16 \mathrm{~kg}$ ). Ethylene Vinyl Acetate-ZnO nanocomposites were prepared for different weight percentage (1\%, $2 \%$, and $4 \%$ ) of $\mathrm{ZnO}$ by direct probe sonicator method. Initially pure EVA film was made in a glass mould by solvent casting method using toluene. Then $1 \%$ by weight of $\mathrm{ZnO}$ nanoparticles was added to EVA- toluene mixture taken in a beaker and was subjected to direct probe sonication. Finally 


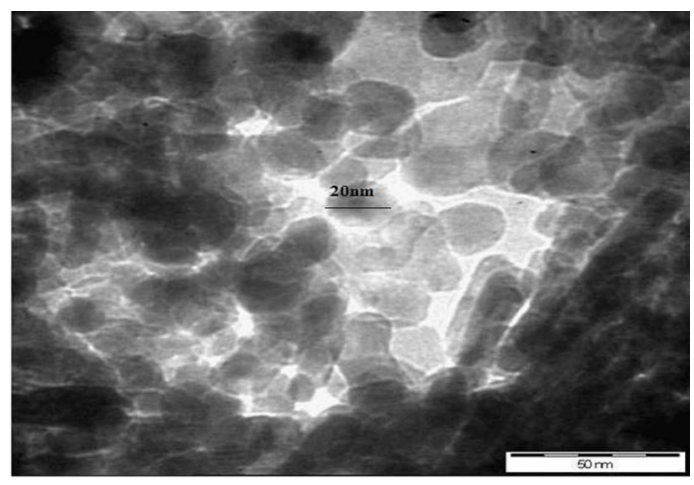

Figure 1. TEM image of $\mathrm{ZnO}$ nanopowder.

the polymer was dried in a glass mould for 3 - 4 hours at $50^{\circ} \mathrm{C}$ and thus polymer nanocomposite with $1 \% \mathrm{ZnO}$ was formed. Similarly nanocomposites for remaining weight percentage, (2\% and $4 \%$ ) of $\mathrm{ZnO}$ were prepared.

\section{Results and Discussion}

\subsection{Morphological Studies}

TEM micrograph shown in Figure 1 confirmed that the synthesized $\mathrm{ZnO}$ powder are solid in nature and obtained particle size is about $20 \mathrm{~nm}$. SEM micrographs were used to identify the relative differences in surface characteristics of EVA and its nanocomposites. The $\mathrm{ZnO}$ particle distribution and its influence on the EVA copolymer morphology were also investigated. The interaction between $\mathrm{ZnO}$ with host matrix is strong and the surface micelles are homogeneous. Micrographs at $10 \mu \mathrm{m}$ and $1 \mu \mathrm{m}$ showed the developed shape of the EVA particles and the filler distribution in EVA as shown in Figure 2(b) \& Figure 2(c). A homogeneous dispersion of $\mathrm{ZnO}$ in the EVA matrix was observed in Figure 2(a). The nano ZnO dispersion in the EVA surface was evident with higher magnification at $100 \mathrm{~nm}$.

\subsection{Electrical and Optical Properties}

The ZnO/EVA polymer nanocompsite of area $15 \mathrm{~mm}^{2}$ having silver coating on the opposite faces was introduced between two copper electrodes and then connected to HIOKI 3532-50 LCR Impedance analyzer for dielectric measurement. The dielectric constant of the sample is calculated using the relation $€_{\mathrm{r}}=\mathrm{Cd} / €_{0} \mathrm{~A}$; where the nanocomposite acts as a dielectric with $€_{0}$ the absolute permittivity, $C$ is the capacitance, $d$ is the thickness and $\mathrm{A}$ is the area $\left(\mathrm{mm}^{2}\right)$ of the $\mathrm{ZnO} / \mathrm{EVA}$ composite. Figure 3 shows the variation of dielectric constant of $\mathrm{ZnO} / \mathrm{EVA}$ with different filler concentrations. From the figure one can easily examine the behaviour of dielectric constant of nanocomposites with varying frequency from $100 \mathrm{~Hz}$ to $5 \mathrm{MHz}$. It is observed that initially the dielectric constant has larger values at lower frequencies and then decreases with increase in frequency for all films; however there is an increase in the dielectric constant of the nanocomposites as the percentage of the filler concentrations increases. The value of dielectric constant at $1 \mathrm{KHz}$ for $1 \%, 2 \%$ and $4 \%$ are around 3.62, 4.1 and 4.87 respectively. The dielectric constant remains almost constant for all samples in the higher frequencies. At low frequencies, all the four polarizations are active. The space charge contribution depends on the purity and perfection of the material and its influence is noticeable in the low frequency region. The orientational effect can sometimes be seen in some materials even up to $10^{10} \mathrm{~Hz}$. Ionic and electronic polarizations always exist below $10^{13} \mathrm{~Hz}$. Hence, the larger values of dielectric constant and dielectric loss exhibited by nanocomposite at low frequencies may be attributed to space charge polarization due to impurities and defects present in the nanocomposites. Figure 4 shows the variation of dielectric loss of nanocomposites as a function of frequency. In the lower frequency region, dielectric loss shows larger values due to the loss associated with ionic mobility. The trend in the variations of both dielectric constant and dielectric loss as a function of frequency is the same. Temperature has a striking effect on the dielectric properties. Interestingly, the variations of both dielectric constant and dielectric loss as a function of frequency are the same for all temperatures. It is observed that the dielectric constant and dielectric loss slightly decrease with the temperature which may due to the reduction in charge carriers. The variation of dielectric constant and loss with temperatures for $1 \mathrm{KHz}$ and $2 \mathrm{KHz}$ frequency 


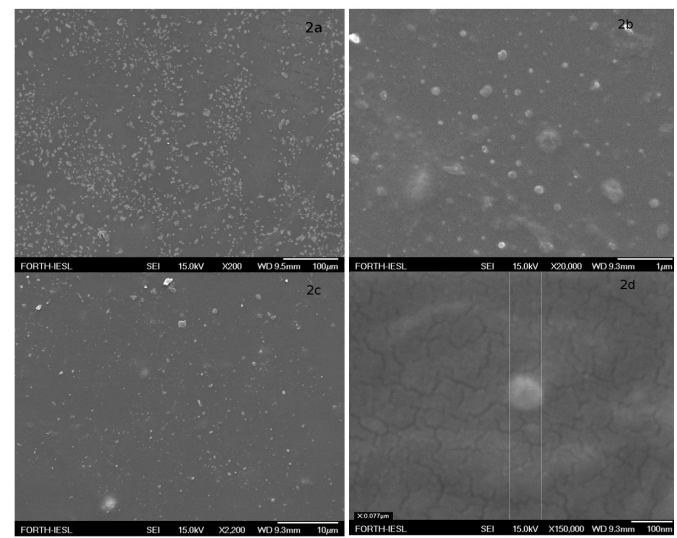

Figure 2. (a)-(d) SEM Micrographs of ZnO/EVA nanocomposite in different magnifications.

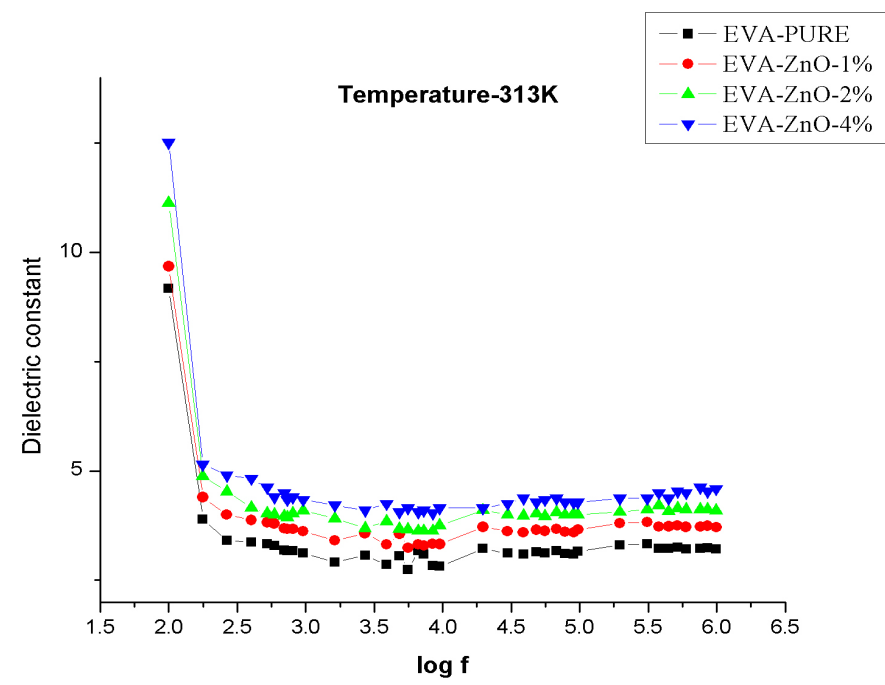

Figure 3. Variation of dielectric constant of $\mathrm{ZnO} / \mathrm{EVA}$ with different filler concentrations as a function of frequency.

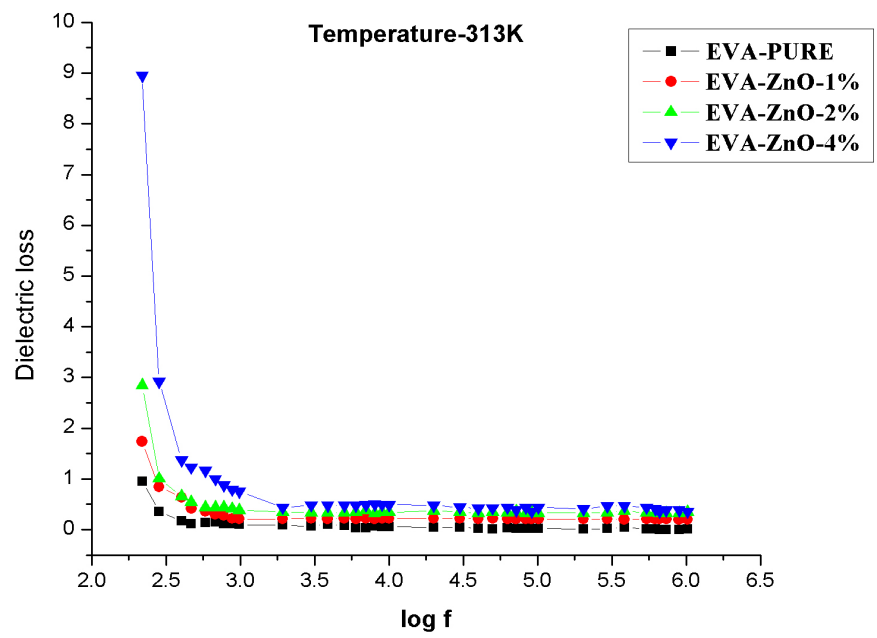

Figure 4. Variation of dielectric loss of $\mathrm{ZnO} / \mathrm{EVA}$ with different filler concentrations as a function of frequency. 
are shown in Figures 5-8.

The optical absorption coefficients of the nanocomposites are done using VARIAN CARY 5000 spectrophotometer in the range of 200 to $2000 \mathrm{~nm}$ and are shown in Figure 9. The spectra show large transparency window between $500 \mathrm{~nm}$ and $1600 \mathrm{~nm}$. But there is a absorption at 1200 and $1450 \mathrm{~nm}$. It is observed that the intensity of the absorption peak is increased with increasing the filler concentrations. The band gap of the PNC's are calculated using Tauc plotting technique and is shown in Figure 10. The band gaps of $1 \%, 2 \%$ and $4 \% \mathrm{EVA} / \mathrm{ZnO}$ PNC's are found to be $4.56 \mathrm{eV}, 4.18 \mathrm{eV}$ and $3.97 \mathrm{eV}$ respectively, which decreases with increasing filler concentrations thus increases the conductivity by increasing the $\mathrm{ZnO}$ concentration.

The analysis of Fourier transform infrared (FT-IR) spectra of the samples have been carried out using a Thermo Nicolet Make Avatar 370 FTIR Spectrometer in the wave number range $400-4000 \mathrm{~cm}^{-1}$. DTGS detector is used for signal Detection. Figures 11(a)-(c) show the FT-IR spectra of pristine EVA and $2 \%$ \& $4 \%$ $\mathrm{ZnO} / \mathrm{EVA}$ nanocomposites. The spectrum of the nanocomposites exhibits the characteristics absorption bands

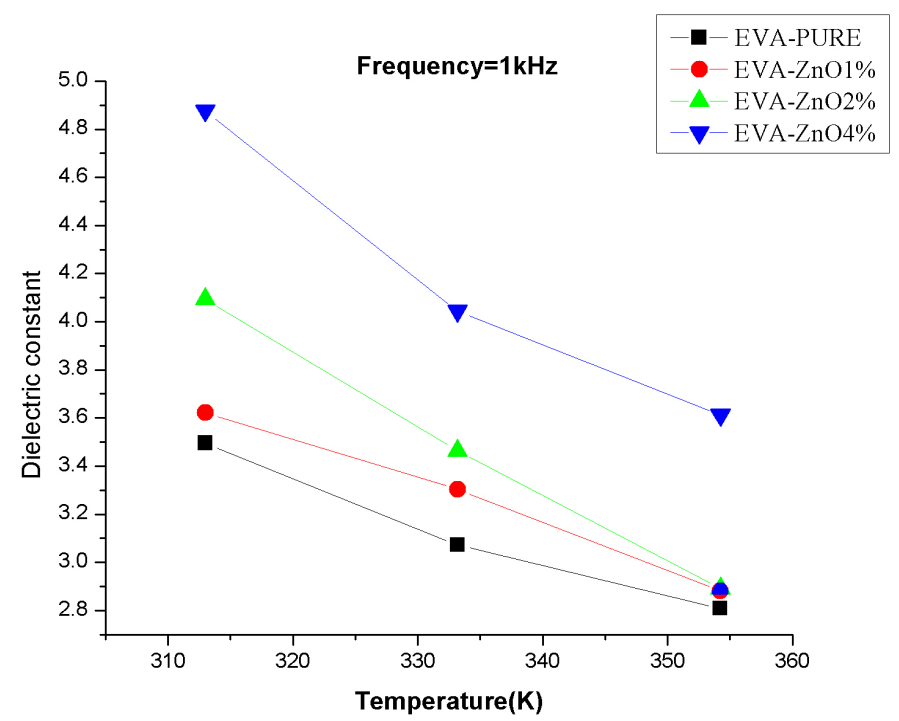

Figure 5. Variation of dielectric constant of ZnO/EVA with different temperature at $1 \mathrm{KHz}$ frequency.

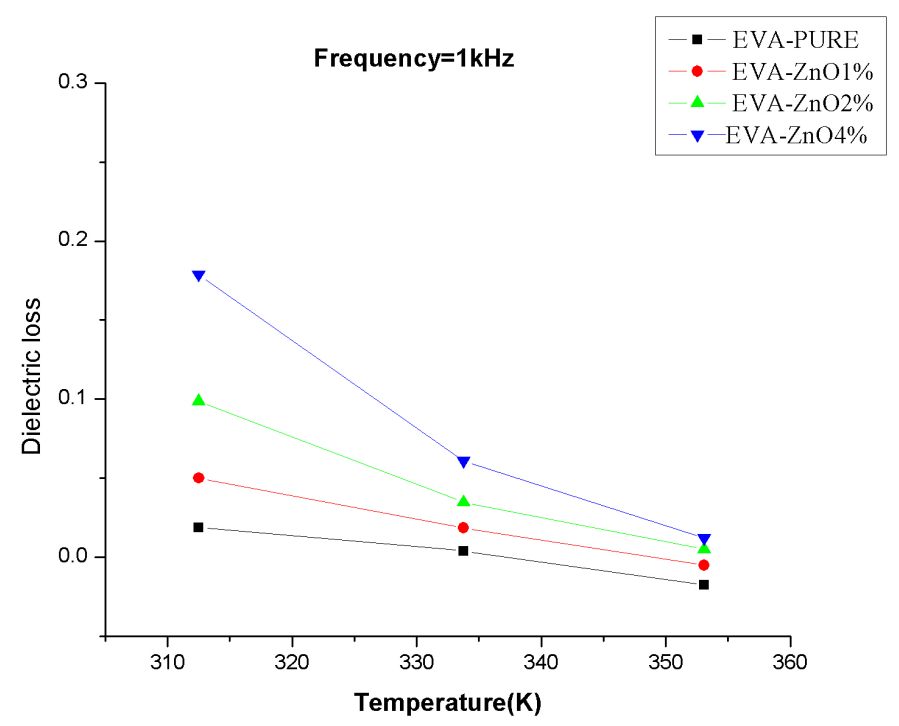

Figure 6. Variation of dielectric loss of $\mathrm{ZnO} / \mathrm{EVA}$ with different temperature at $1 \mathrm{KHz}$ frequency. 


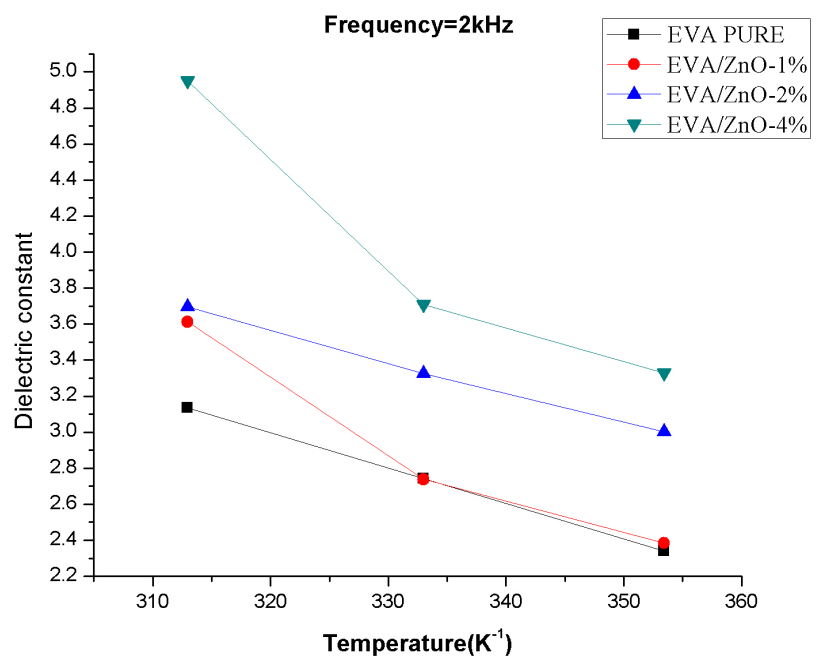

Figure 7. Variation of dielectric constant of $\mathrm{ZnO} / \mathrm{EVA}$ with different temperature at $2 \mathrm{KHz}$ frequency.

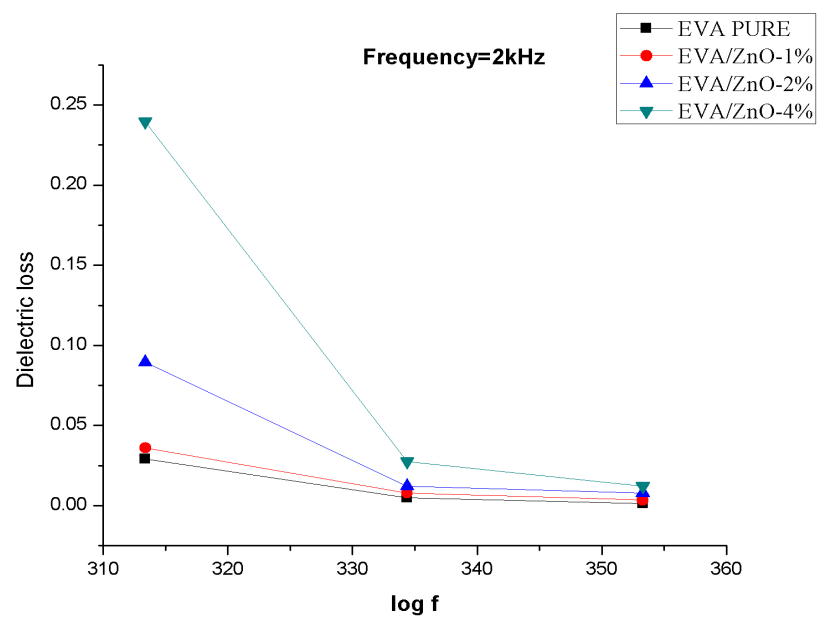

Figure 8. Variation of dielectric loss of $\mathrm{ZnO} / \mathrm{EVA}$ with different temperature at $2 \mathrm{KHz}$ frequency.

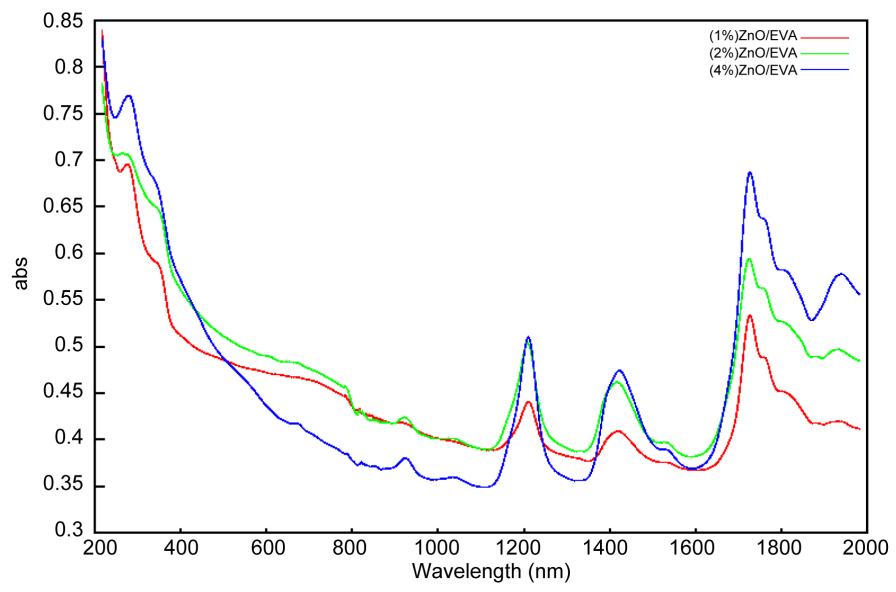

Figure 9. UV-Vis-NIR spectra of EVA/ZnO Nanocomposite with different filler concentrations. 


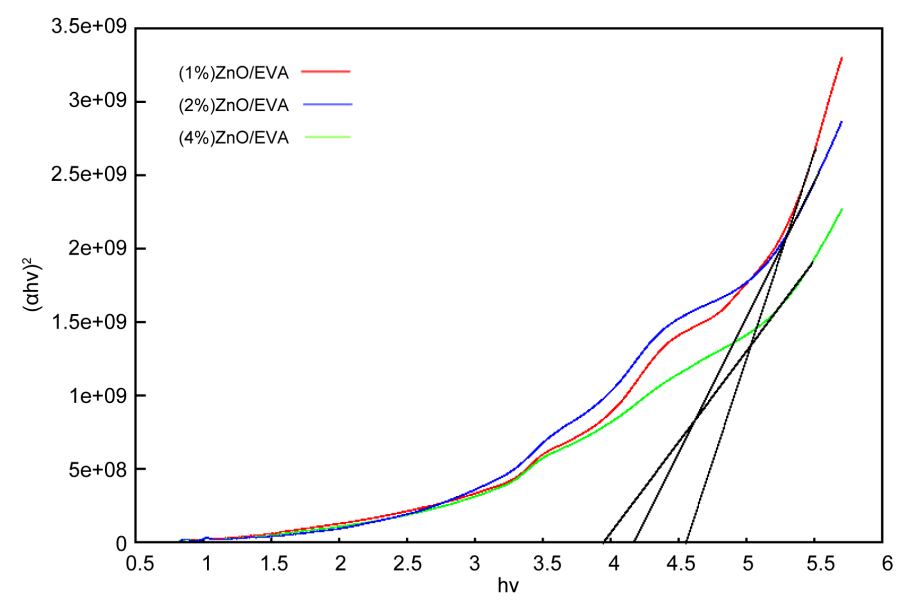

Figure 10. Tauc plot of EVA/ZnO nanocomposite with different filler concentrations.

corresponding to polymer groups and $\mathrm{ZnO}$ nanoparticles. In following spectra of $\mathrm{ZnO} / \mathrm{EVA}$ composites, the transmittance intensity changes at $479.24 \mathrm{~cm}^{-1}, 444.73 \mathrm{~cm}^{-1}$ and $434 \mathrm{~cm}^{-1}$ are corresponding to Zn-O vibrations. The bands centered at $1371.96 \mathrm{~cm}^{-1}$ and $1163.75 \mathrm{~cm}^{-1}$ are indicates the transmittance intensity is increased and is attributed to the stretching vibrations of $\mathrm{C}=\mathrm{O}$ and $\mathrm{C}-\mathrm{H}$ groups in acetate species.

The characteristics vibration bands of aromatic $C=C$ units are observed at $1465.70 \mathrm{~cm}^{-1}$ in the spectra of EVA and $\mathrm{ZnO} / \mathrm{EVA}$ has changed as increasing percentages of $\mathrm{ZnO}$ nanoparticles and extra peaks are observed at $1566.25 \mathrm{~cm}^{-1}$ and $1624.13 \mathrm{~cm}^{-1}$. The band centered at $2920 \mathrm{~cm}^{-1}$ and $2850.28 \mathrm{~cm}^{-1}$ are observed in EVA and $\mathrm{ZnO} / \mathrm{EVA}$ spectra are the stretching vibrations of $\mathrm{C}-\mathrm{H}$ alkanes. There is a specific peak is observed in the spectrum of both $2 \%$ and $4 \% \mathrm{ZnO} / \mathrm{EVA}$ at $3431.14 \mathrm{~cm}^{-1}$ and $3396.19 \mathrm{~cm}^{-1}$ which emphasized the O-H bond stretching of $\mathrm{ZnO}$ nanofillers. The changes in the relative intensities of the bands in the region $1420.31 \mathrm{~cm}^{-1}, 1115 \mathrm{~cm}^{-1}$ and $902.61 \mathrm{~cm}^{-1}$ in composite can be due to the presence of absorbed species on the surface of the $\mathrm{ZnO}$ nanoparticles. The characteristics bands of EVA and $\mathrm{ZnO}$ are both observed in the ZnO/EVA spectrum which confirmed that $\mathrm{ZnO}$ is well dispersed in the EVA matrix.

\subsection{Thermal Studies}

The TGA and DTA analyses of polymer nanocomposites were carried out between $28^{\circ} \mathrm{C}$ and $1300^{\circ} \mathrm{C}$ at a heating rate of $20 \mathrm{~K} / \mathrm{min}$ using the instrument NETSZCH STA 409C. The TGA-DTA curves are shown in Figures 12(a)-(d), which confirms the decomposition of the nanocomposites occurs in two steps. $28.9 \%$ and $28.5 \%$ of weight is lost for Pure EVA and 1\% added composite respectively in the first stage while that of $14 \%$ and $13 \%$ respectively for $2 \%$ and $4 \%$ of filler concentrations. It is also observed that the thermal stability of the polymer nanocomposites increases with increasing the filler concentrations and the onset decomposition temperature of the pure EVA, $1 \%, 2 \%$ and $4 \%$ are around $290^{\circ} \mathrm{C}, 295^{\circ} \mathrm{C}, 318^{\circ} \mathrm{C}$ and $337^{\circ} \mathrm{C}$ respectively. There is no much difference in the thermogram of Pure and $1 \%$ doped $\mathrm{ZnO}$. The increment in the thermal stability may be due to the increase in the strength of the nanocomposite by increase of interfacial area.

The thermal parameters such as thermal diffussivity $(\alpha)$ and thermal efffusivity (e), the thermal conductivity (k) and heat capacity $\left(\mathrm{C}_{\mathrm{p}}\right)$ were determined by the technique developed Preethy $\mathrm{C}$ menon et al. [25]. During the measurement the sample, the pyroelectric detector and the backing should be thermally thick. The sample was illuminated by an intensity-modulated beam of light, which gives rise to periodic temperature variation by optical absorption. The thermal waves so generated propagate through the sample and were detected by the pyroelectric detector.

A He-Cd laser of (wavelength $\lambda=442 \mathrm{~nm}$ KIMMON) output power $120 \mathrm{~mW}$ was used as the optical heating source. A polyvinylidene difluoride (PVDF) film of thickness $28 \mu \mathrm{m}$ was used as the pyroelectric detector. The sample was attached to the pyroelectric detector by means of a thermally thin layer of a compound whose contribution to the signal was negligible. The signal output was measured using a lock-in amplifier (SR830). The frequency of modulation of the light was kept above $40 \mathrm{~Hz}$ to ensure that the detector, the sample and the backing 


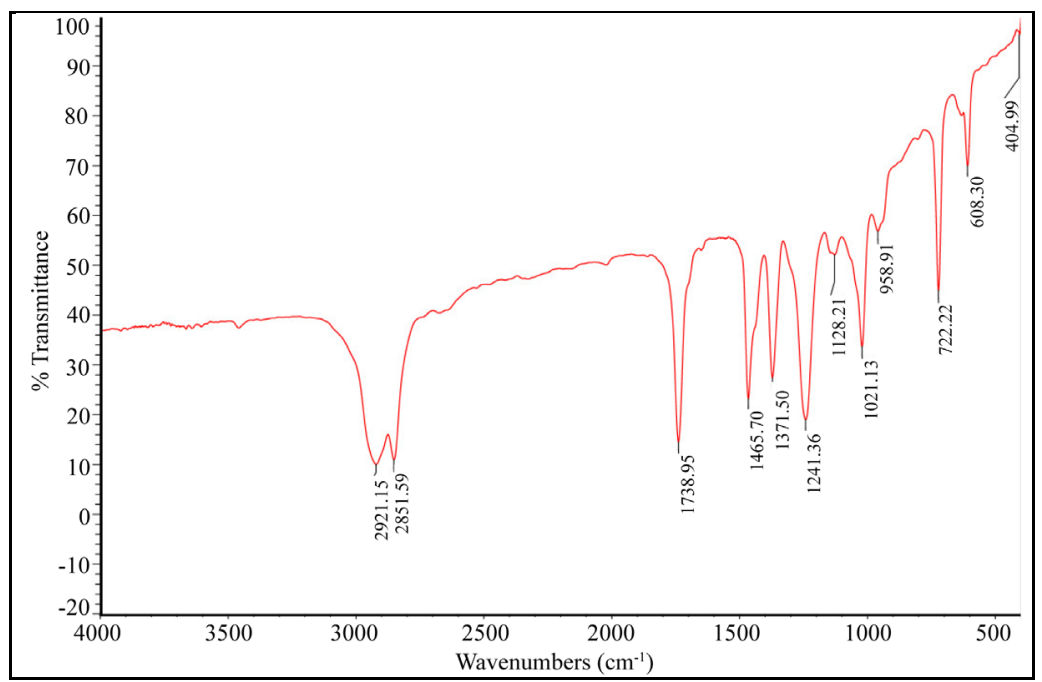

(a)

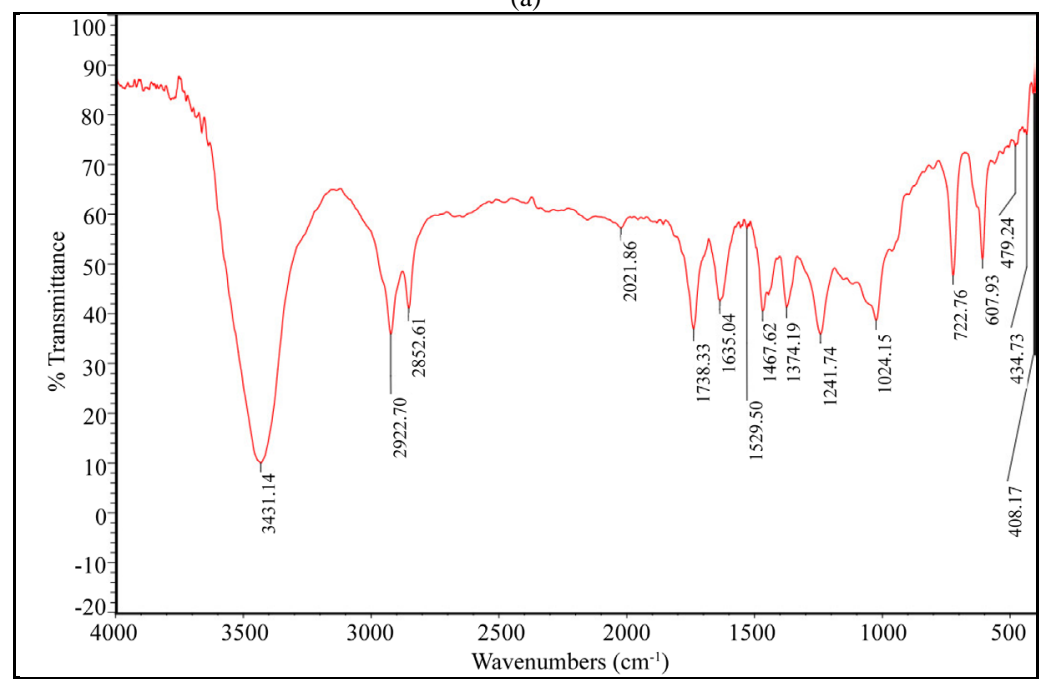

(b)

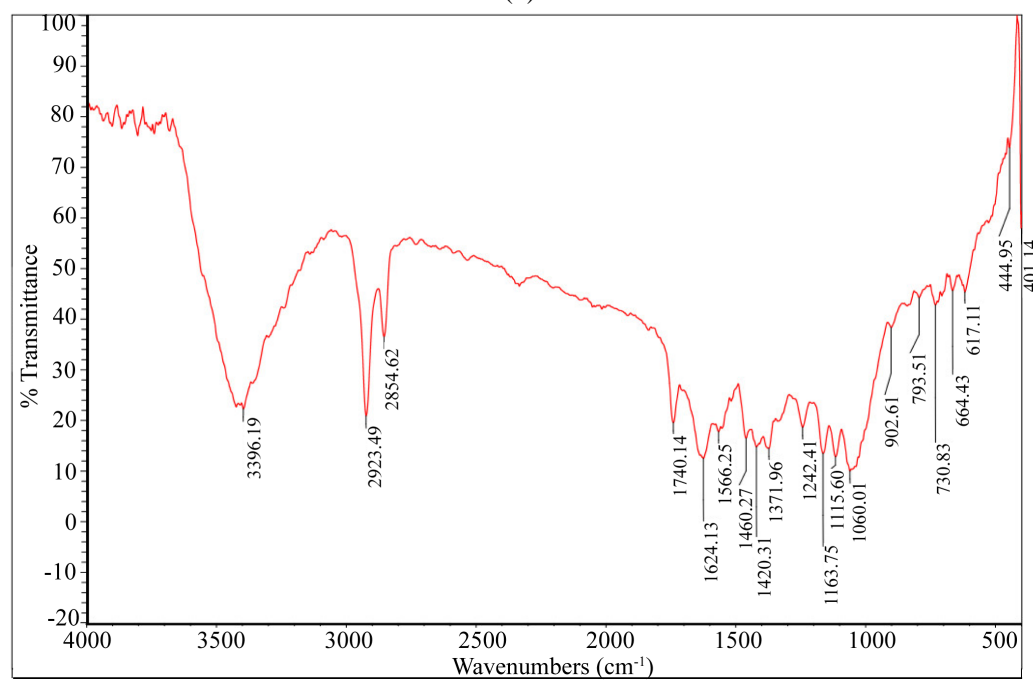

(c)

Figure 11. (a)-(c) The comparison of FT-IR Spectra of pure EVA, 2\%ZnO/EVA and $4 \% \mathrm{ZnO} / \mathrm{EVA}$ polymer nanocomposites. 
J. Sebastian et al.

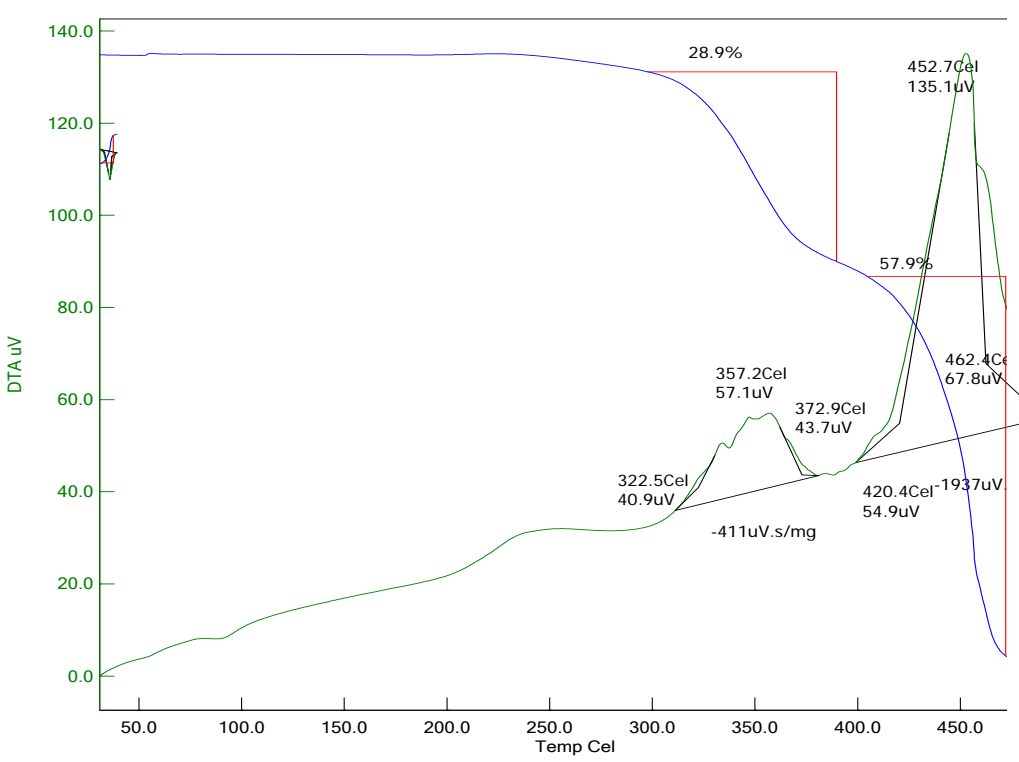

(a)

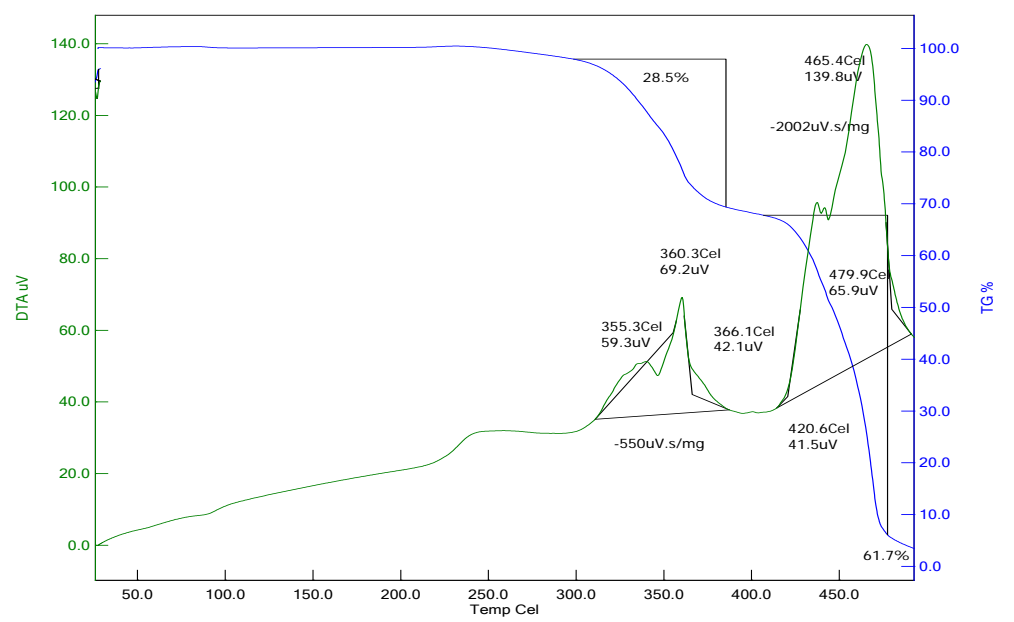

(b)

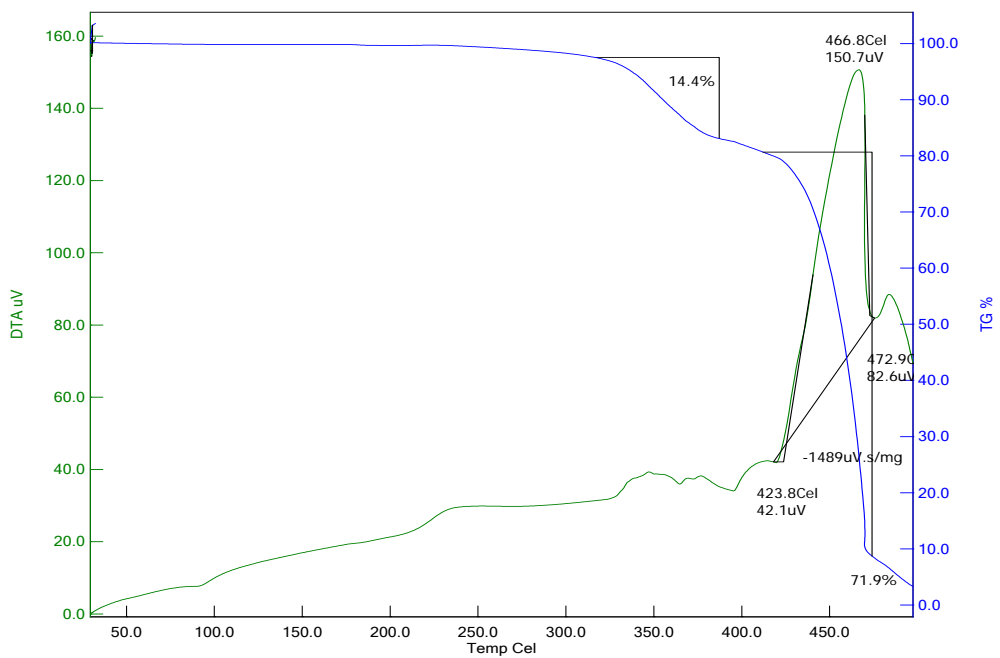

(c) 


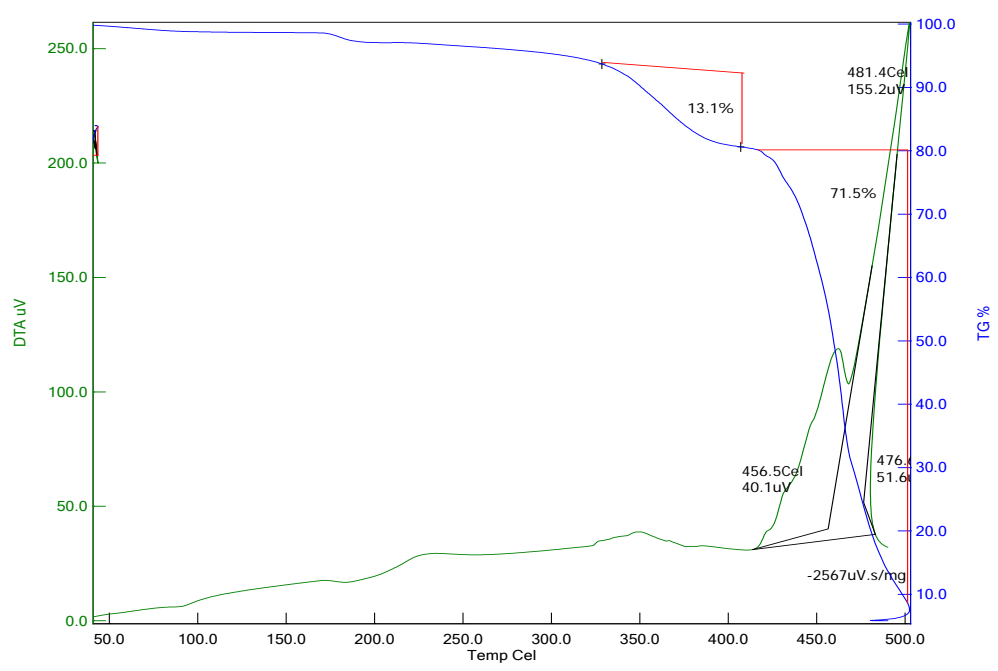

(d)

Figure 12. (a) TGA-DTA Curve of pure EVA; (b) TGA-DTA Curve of EVA-ZnO 1\%; (c) TGA-DTA Curve of EVA-ZnO 2\%; (d) TGA-DTA Curve of EVA-ZnO 4\%.

medium were thermally thick during measurements. The values of the thermal parameters such as thermal effussivity (e) and thermal diffusivity $(\alpha)$, the thermal conductivity $(\mathrm{k})$ and heat capacity for $2 \% \mathrm{ZnO}$ are $1637 \pm 18$ $\mathrm{Ws}^{1 / 2} / \mathrm{m}^{2} \mathrm{~K}, 2.4154 \pm 0.14 \times 10^{-6} \mathrm{~m}^{2} / \mathrm{s}, 2.63 \pm 0.10 \mathrm{~W} / \mathrm{mK}$ and $1431 \pm 33 \mathrm{~J} / \mathrm{kgK}$ respectively while that of $4 \%$ are $2758 \pm 35 \mathrm{Ws}^{1 / 2} / \mathrm{m}^{2} \mathrm{~K}, 8.5113 \pm 0.18 \times 10^{-6} \mathrm{~m}^{2} / \mathrm{s}, 7.98 \pm 0.15 \mathrm{~W} / \mathrm{mK}$ and $1300 \pm 28 \mathrm{~J} / \mathrm{kgK}$ respectively. When we doubled the filler concentration the value of thermal parameters has got enhanced whereas the specific heat capacity decreased.

\subsection{Mechanical Properties}

The tensile strength and elongation at break of the virgin EVA and EVA nanocomposites samples were performed using an Instron 3366 testing machine according to ASTM D882. Each sample had a width of $6.4 \mathrm{~mm}$. The average thickness of the samples was about $0.060 \mathrm{~mm}$. The tensile test was conducted using a cross head speed of $1.3 \mathrm{~mm} / \mathrm{min}$. The stress- strain graph and elongation at various stages of the test was recorded and shown in Figure 13. Ethylene vinyl acetate (EVA) films shows good tensile strength (30 MPa) and stretches $430 \%$ to its original dimension before break. Thin films of EVA-ZnO nanocomposites have got comparable tensile and deforming properties to that of the virgin polymer. The tensile strength improves to $33 \mathrm{MPa}$ on addition of $1 \%$ of $\mathrm{ZnO}$ nanoparticles. The nano sized particles tend to tie up the EVA molecules, leading to greater resistance to the tensile deformations. Further increase in $\mathrm{ZnO}$, reduces the tensile strength and the strain deformations. The chain flexibility of the macromolecules might have been reduced with the incorporation of $\mathrm{ZnO}$ nanoparticles, leading to reduction of elongation.

Peel strength of the nanaocomposites were performed using an Instron tensile testing machine at a peel speed of $50 \mathrm{~mm} / \mathrm{min}$. Peel test with $180^{\circ}$ stripping is carried out as per ASTM D 1876. Peel test involves stripping away of substrate joined by the adhesive. The substrates (glass paper, cotton and polyester) were flexible enough to permit a $180^{\circ}$ turn near the point of loading. Peel strength values was recorded in Newton per millimeter $(\mathrm{N} / \mathrm{mm})$ of width of the bonded specimen. Peel strength of the EVA nanocomposites on various substrates are shown in Figure 14. The inclusion of the $\mathrm{ZnO}$ nanoparticles to the EVA matrix improves its peel strength on $2 \%$ of nano $\mathrm{ZnO}$ loading on all substrates. When $\mathrm{ZnO}$ is added more, it is found that the peel adhesion properties get reduced compared to the virgin compound. The surface finish and smoothness of the glass paper might have attributed to its inferior adhesion compared cotton and polyester fabric. Cotton fabric gives maximum peel adhesion $(2.4 \mathrm{~N} / \mathrm{mm})$ as the EVA copolymer impregnate on its porous surface.

\section{Conclusion}

The EVA/ZnO nanocomposites materials of different concentrations of $\mathrm{ZnO}$ nanoparticle $(0 \%, 1 \%, 2 \%$ and $4 \%)$ 


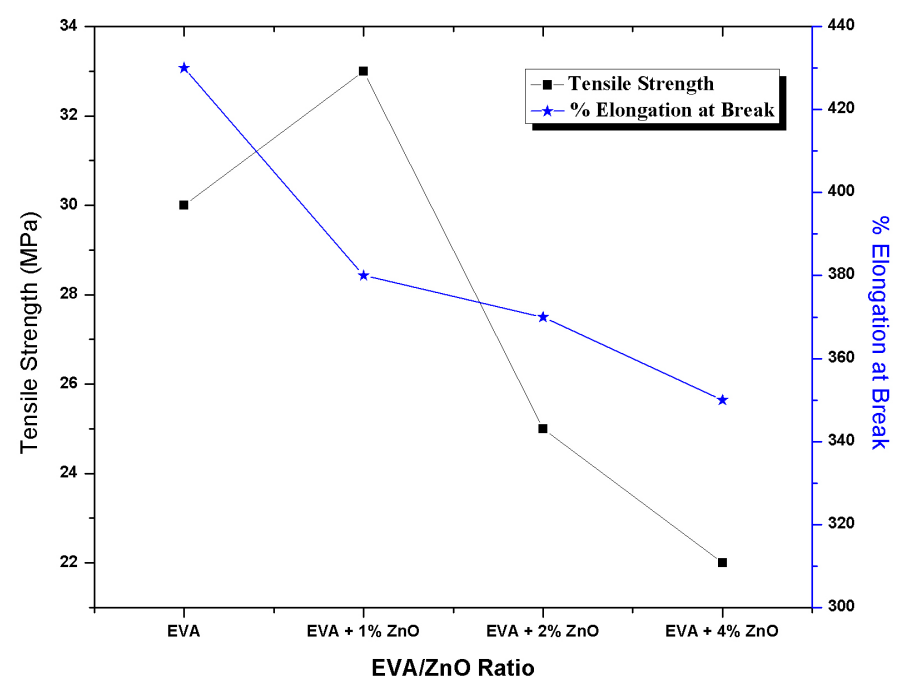

Figure 13. Tensile strength and Elongation at break of EVA/ZnO nanocomposite.

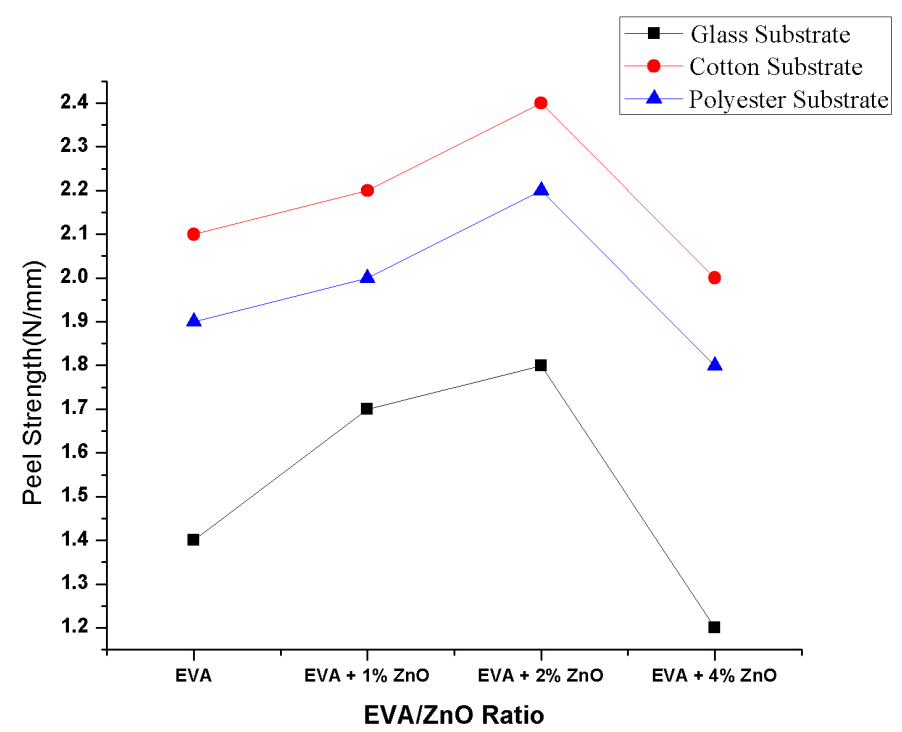

Figure 14. Peel strength of EVA/ZnO nanocomposite.

have been prepared successfully by ultrasonic probe method. The $\mathrm{ZnO}$ nanoparticles used in the synthesis of polymer nanocomposite were synthesized using solvothermal method. The investigations on the electrical properties of the nanocomposites revealed that the conductivity increases with increasing the filler concentrations and resistivity increases with increasing the temperature. The band gap of the nanocomposites found to be decreased with increasing the filler concentration. The thermal stability of the nanocomposites was also found to be increased. Photopyroelectric Technique is used to find the thermal parameters such as such as thermal diffussivity $(\alpha)$ and thermal efffusivity (e), the thermal conductivity $(\mathrm{k})$ and heat capacity $\left(\mathrm{C}_{\mathrm{p}}\right)$ and except heat capacity all others found to be increased with increasing the filler concentrations. The tensile strength and peel strength of the nanocomposites found to increase initially with the addition of $\mathrm{ZnO}$ nanomaterials. On further addition of $\mathrm{ZnO}$, the mechanical properties drop down.

\section{References}

[1] Ray, S., Easteal, A.J., Cooney, R.P. and Edmonds, N.R. (2009) Structure and Properties of Melt-Processed PVDF/ PMMA/Polyaniline Blends. Materials Chemistry and Physics, 113, 829-838. 
http://dx.doi.org/10.1016/j.matchemphys.2008.08.034

[2] Blom, P.W.M., Schoo, H.F.M. and Matters, M. (1998) Electrical Characterization of Electroluminescent Polymer/ Nanoparticle Composite Devices. Applied Physics Letters, 73, 3914. http://dx.doi.org/10.1063/1.122934

[3] Kiesow, A., Morris, J.E., Radehaus, C. and Heilmann, A. (2003) Switching Behavior of Plasma Polymer Films Containing silver Nanoparticles. Journal of Applied Physics, 94, 6988. http://dx.doi.org/10.1063/1.1622990

[4] Siegel, R.W., Schadler-Feist, L., Ma, D., Hong, J.I., Martensson, E. and Onneby, C. (2005) Nanocomposites with controlled Electrical Properties. Publication No: WO2005036563, 28 p.

[5] Murugaraj, P., Mainwaring, D. and Mora-Huertas, N. (2005) Dielectric Enhancement in Polymer-Nanoparticle Composites through Interphase Polarizability. Journal of Applied Physics, 98, 054304. http://dx.doi.org/10.1063/1.2034654

[6] Tishkova, V., Raynal, P.-I., Puech, P., Lonjon, A., Le Fournier, M., Demont, P., Flahaut, E. and Basca, W. (2011) Electrical Conductivity and Raman Imaging of Double Wall Carbon Nanotubes in a Polymer Matrix. Composites Science and Technology, 71, 1326-1330. http://dx.doi.org/10.1016/j.compscitech.2011.05.001

[7] Lee, J., Sunder, V.C., Heine, J.R., Bawendi, M.G. and Jensen, K.F. (2000) Full Color Emission from II-VI Semiconductor Quantum Dot-Polymer Composites. Advanced Materials, 12, 1102. http://dx.doi.org/10.1002/1521-4095(200008)12:15<1102::AID-ADMA1102>3.0.CO;2-J

[8] Shaheen, S.E., Brabec, C.J., Sariciftci, N., et al. (2001) 2.5\% Efficient Organic Plastic Solar Cells. Applied Physics Letters, 78, 841-843. http://dx.doi.org/10.1063/1.1345834

[9] Wang, H. and Branton, D. (2001) Nanopores with a Spark for Single-Molecule Detection. Nature Biotechnology, 19, 622-623. http://dx.doi.org/10.1038/90216

[10] Artemyeu, M., Woggon, U. and Langbein, W. (2002) Quantum Dot Emission Confined by a Spherical Photonic Dot. Physica Status Solidi (b), 229, 423-426. http://dx.doi.org/10.1002/1521-3951(200201)229:1<423::AID-PSSB423>3.0.CO;2-\#

[11] Klein, D., Roth, R., Lim, A.K.L., Alivisatos, A.P. and McEuen, P.L. (1997) A Single-Electron Transistor Made from a Cadmium Selenide Nanocrystal. Nature, 389, 699-701. http://dx.doi.org/10.1038/39535

[12] Klimov, V.I., Milkhailovsky, A.A., Xu, S. Leatherdale, C.A., Eisler, H.J. and Bawendi, M.G. (2000) Optical Gain and Stimulated Emission in Nanocrystal Quantum Dots. Science, 290, 314-317. http://dx.doi.org/10.1126/science.290.5490.314

[13] Konenkamp, R., Word, R. and Schlegel, C. (2004) Vertical Nanowire Light-Emitting Diode. Applied Physics Letters, 85, 6004. http://dx.doi.org/10.1063/1.1836873

[14] Dang, Z.M., Zhou, T., Yao, S.H., Yuan, J.K., Zha, J.W. and Song, H.T. (2009) Advanced Calcium Copper Titanate/ Polyimide Functional Hybrid Films with High Dielectric Permittivity. Advanced Materials, 21, 2077-2082. http://dx.doi.org/10.1002/adma.200803427

[15] Dang, Z.M., Yuan, J.K., Zha, J.W., Zhou, T., Li, S.T. and Hu, G.H. (2012) Fundamentals, Processes and Applications of High-Permittivity Polymer-Matrix Composites. Progress in Materials Science, 57, 660-723. http://dx.doi.org/10.1016/j.pmatsci.2011.08.001

[16] Monti, O.L.A., Fourkas, J.T. and Nesbitt, D.J. (2004) Diffraction-Limited Photogeneration and Characterization of Silver Nanoparticles. The Journal of Physical Chemistry B, 108, 1604-1612. http://dx.doi.org/10.1021/jp030492c

[17] Yuen, S.M., Ma, C.C.M., Chuang, C.Y., Yu, K.C., Wu, S.Y., Yang, C.C. and Wei, M.H. (2008) Effect of Processing Method on the Shielding Effectiveness of Electromagnetic Interference of MWCNT/PMMA Composites. Composites Science and Technology, 68, 963-968. http://dx.doi.org/10.1016/j.compscitech.2007.08.004

[18] Stankovich, S., Dikin, D.A., Dommett, G.H.B., Kohlhaas, K.M., Zimney, E.J., Stach, E.A., Piner, R.D., Nguyen, S.T. and Ruoff, R.S. (2006) Graphene-Based Composite Materials. Nature, 442, 282-286. http://dx.doi.org/10.1038/nature04969

[19] Khanna, P.K., Singh, N., Charan, S. and Mulik, U.P. (2005) Synthesis and Characterization of Ag/PVA Nanocomposite by Chemical Reduction Method. Materials Chemistry and Physics, 93, 117-121.

[20] Bhadra, S., Khastgir, D., Singha, N.K. and Lee, J.H. (2009) Progress in Preparation, Processing and Applications of Polyaniline. Progress in Polymer Science, 34, 783-810. http://dx.doi.org/10.1016/j.progpolymsci.2009.04.003

[21] Subramanian, S. and Pathinettam Padiyan, D. (2008) Effect of Structural, Electrical and Optical Properties of Electrodeposited Bismuth Selenide Thin Films in Polyaniline Aqueous Medium. Materials Chemistry and Physics, 107, $392-$ 398. http://dx.doi.org/10.1016/j.matchemphys.2007.08.005

[22] Gonzalex-Benito, J., Castillo, E. and Caldito, J.F. (2013) Coefficient of Thermal Expansion of $\mathrm{TiO}_{2}$ Filled EVA Based Nanocomposites. A New Insight about the Influence of Filler Particle Size in Composites. European Polymer Journal, 49, 1747-1752. http://dx.doi.org/10.1016/j.eurpolymj.2013.04.023 
[23] Chu, K.C., Jordan, K.J., Battista, J.J., Van-Dyk, J. and Rutt, B.K. (2000) Polyvinyl Alcohol-Fricke Hydrogel and Cryogel: Two New Gel Dosimetry Systems with Low Fe ${ }^{3+}$ Diffusion. Physics in Medicine and Biology, 45, 955. http://dx.doi.org/10.1088/0031-9155/45/4/311

[24] Kasap, S. (2007) Springer Handbook of Electronic and Photonic Materials. Springer, Berlin. http://dx.doi.org/10.1007/978-0-387-29185-7

[25] Preethy Menon, C. and Philip, S. (2000) Simultaneous Determination of Thermal Conductivity and Heat Capacity Near Solid State Phase Transitions by a Photopyroelectric Technique. Measurement Science and Technology, 11, 1744. http://dx.doi.org/10.1088/0957-0233/11/12/314 